\title{
The oldest representative of a modern deep-sea ophiacanthid brittle-star clade from Jurassic shallow-water coral reef sediments
}

\author{
Ben Thuy and Hartmut Schulz \\ Acta Palaeontologica Polonica 58 (3), 2012: 525-531 doi: http://dx.doi.org/10.4202/app.2011.0192
}

Ophiurites crinitus is a fossil brittle-star species which passed largely unnoticed since its original description. In this paper, we redescribe the type material of $O$. crinitus with the aim to put it into the context of modern ophiuroid systematics, and propose the new genus name Ophiosternle to replace the invalid Ophiurites. The re-assessed species is shown to be a member of the extant deep-sea family Ophiacanthidae, articulated fossils of which are extremely rare. It presents greatest affinities with members of the Ophioplinthaca-Ophiocamax-Ophiomitra clade, of which it most probably represents the oldest known fossil species. The depositional environment of the strata, which yielded the described specimens is interpreted as shallow, storm-influenced marine setting in the immediate vicinity of coral reefs. This contrasts with the distribution pattern of extant species of the Ophioplinthaca-Ophiocamax-Ophiomitra clade, which almost exclusively occur at depths exceeding the shelf break.

Key words: Echinodermata, Ophiuroidea, Ophiacanthidae, coral reef, deep-sea group, Jurassic, Mergelstetten Formation, Germany.

Ben Thuy [nebyuht@yahoo.com], Geoscience Institute, University of Göttingen, Department of Geobiology, Goldschmidtstrasse 3, D-37077 Göttingen, Germany; Hartmut Schulz [hartmut.schulz@uni-tuebingen.de], Department of Geosciences, University of Tübingen, Paleobiology, Hölderlinstrasse 12, D-72074 Tübingen, Germany.

This is an open-access article distributed under the terms of the Creative Commons Attribution License (for details please see creativecommons.org), which permits unrestricted use, distribution, and reproduction in any medium, provided the original author and source are credited. 
FoF Full text $(463.7 \mathrm{kB})$ 